\title{
Mapeamento do processo produtivo de erva-mate
}

\author{
Eraldo Antonio Bonfatti Júnior'; Elaine Cristina Lengowski; Aderbal Ludka Júnior ${ }^{2}$
}

$\triangle$ bonfattieraldo@gmail.com

1. Universidade Federal do Paraná, Curitiba - PR

2. Universidade do Contestado, Canoinhas - SC

\section{Histórico do Artigo:}

Recebido em: 29 de janeiro de 2018

Aceito em: 04 de maio de 2018

Publicado em: 30 de junho de 2018

Resumo: A erva-mate é uma espécie florestal característica da região sul do Brasil que proporciona renda aos produtores rurais, sendo o principal produto florestal não madeireiro daquela região. Com a competitividade do mercado o mapeamento de processo produtivo surge como uma estratégia avançada para que as empresas possam enxergar as suas falhas a fim de encontrar as soluções na busca por melhor produtividade e maior rentabilidade financeira. Diante disso, esse trabalho propôs avaliar o processo produtivo de uma ervateria de pequeno porte localizada na Região do Contestado, norte do estado de Santa Catarina. Para isso o levantamento de dados contou com observação, visitas à industria e consulta aos responsáveis técnicos pela produção. Dentre as técnicas disponíveis para 0 mapeamento foram utilizados a análise SIPOC, o mapa de processo e o posicionamento dos processos na planta da indústria. A análise SIPOC e o mapeamento de processos como ferramentas gerenciais possibilitaram a visualização dos processos em diferentes escalas, mostrando maior complexidade do processo produtivo de erva-mate padrão uruguaio em relação à erva-mate destinada para 0 mercado interno, o relacionamento entre as atividades e as dimensões e cruzamentos de fluxo dentro da indústria.

Palavras-chave: SIP0C. Layout. Produto florestal não madeireiro. Fluxo.

\section{Mapping of the productive process of mate herb}

\begin{abstract}
The mate herb is a characteristic forest species of the Southern region of Brazil that provides income to the rural producers, being the main non-timber forest product of that region. With the competitiveness of the market the mapping of the productive process emerges as an advanced strategy so that companies can see their failures in order to find the solutions in the search for better productivity and greater financial profitability. In view of this, this work proposes to evaluate the production process of a small-sized store located in the Contestado Region, North of the state of Santa Catarina. For this the data collection included observation, visits to the industry and consultation with the technical responsible for the production. Among the available techniques for the mapping were the SIPOC analysis, the process map and the positioning of the processes in the plant of the industry. The SIPOC analysis and the mapping of processes as managerial tools enabled the visualization of the processes at different scales, showing the high complexity of the Uruguayan mate herb production process in relation to the mate herb intended for the domestic market, the relationship between the activities and the dimensions and crossings of flow within the industry.
\end{abstract}

Keywords: SIPOC. Layout. Non-timber forest product. Flow. 


\section{Mapeo del proceso productivo de yerba mate}

Resumen: La yerba mate es una especie forestal característica de la región sur de Brasil que proporciona renta a los productores rurales, siendo el principal producto forestal no maderero de aquella región. Con la competitividad del mercado el mapeo de proceso productivo surge como una estrategia avanzada para que las empresas puedan ver sus fallas a fin de encontrar las soluciones en la búsqueda de una mejor productividad y una mayor rentabilidad financiera. Frente a ello, este trabajo propone evaluar el proceso productivo de una ervatería de pequeño porte ubicada en la Región del Contestado, norte del estado de Santa Catarina. Para ello el levantamiento de datos contó con observación, visitas a la industria y consulta a los responsables técnicos por la producción. Entre las técnicas disponibles para el mapeo se utilizaron el análisis SIP0C, el mapa de proceso y el posicionamiento de los procesos en la planta de la industria. El análisis SIPOC y el mapeamiento de procesos como herramientas gerenciales posibilitaron la visualización de los procesos en diferentes escalas, mostrando la mayor complejidad del proceso productivo de hierbabuena estándar uruguayo en relación a la yerba mate destinada al mercado interno, la relación entre las actividades y las dimensiones y cruces de flujo dentro de la industria.

Palabras clave: SIPOC. Layout. Producto forestal no maderero. Fluir.

\section{INTRODUÇÃO}

A erva-mate (Ilex paraguariensis St. Hil.) é uma planta pertencente à família Aquifoliácea, a qual envolve unicamente 0 gênero Ilex onde estão classificadas aproximadamente 600 espécies (SOUZA; LORENZI, 2012).

A área de ocorrência natural de erva-mate abrange aproximadamente $540.000 \mathrm{~km}^{2}$ de regiões subtropicais e temperadas da América do Sul, compreendendo territórios do Brasil, Argentina e Paraguai (ESMELINDR0 et al., 2002; MURAKAMI et al., 2013). Só no Brasil estão situados $450.000 \mathrm{~km}^{2}$ do total, incluindo a região centro-norte do Rio Grande do Sul, quase todo o Estado de Santa Catarina, centro-sul e sudoeste do Paraná, sul do Mato Grosso do Sul e manchas em São Paulo, Rio de Janeiro e Minas Gerais (PERALTA; BOURLEGAT, 2012; SOUZA; LORENZI, 2012). A área de ocorrência natural da erva-mate está representada na Figura 1. 


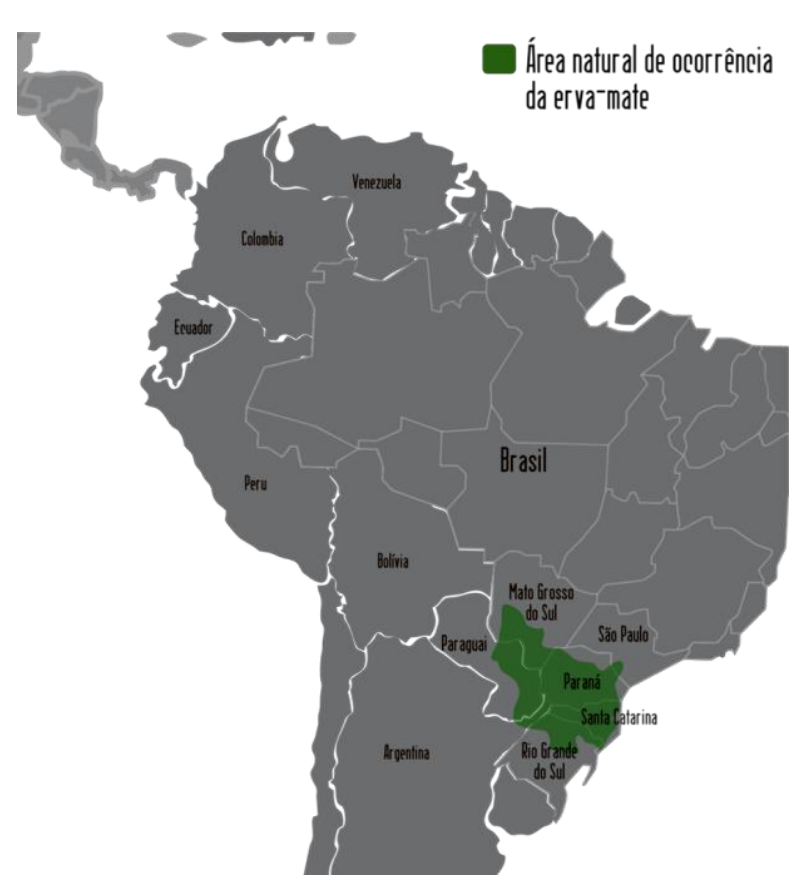

Figura 1. Ocorrência natural da erva-mate Fonte: Catanduvas, 2018

As folhas servem para o preparo de bebidas estimulantes, conhecidas por chimarrão, quando consumida quente, ou tererê, quando consumida fria (SOUZA; LORENZI, 2012; CARDOSO; GROISMAN, 2018), além de servir para chá e como planta medicinal (DIAZ et al., 2013). É matéria-prima para balas, caramelos, sorvetes, refrigerantes, cosméticos, produtos de higiene, medicamentos, corantes e detergentes para uso hospitalar (BORILLE et al., 2005), apesar desses múltiplos produtos, o chimarrão é a principal forma de consumo (BERTÉ, 2011).

A resolução da ANVISA mais recente relacionada a este assunto, RDC ${ }^{0}$ 277, de 22 de setembro de 2005, a qual aprova o "Regulamento Técnico para Café, Cevada, Chá, Erva-Mate e Produtos Solúveis”, preconiza que erva-mate: é o produto constituído exclusivamente pelas folhas e ramos de I. paraguariensis, obtido por processo de secagem e fragmentação destinado ao preparo de "chimarrão" ou "tererê" podendo ser adicionado açúcar.

A erva-mate mostra sua importância em diversas dimensões; socialmente, por estar presente em aproximadamente 180 mil propriedades rurais, sendo a maioria de pequenos produtores, congregando cerca de 600 empresas e 700 mil empregos no Brasil (CHECHI et al., 2017). Além de ser considerada uma espécie com ligação direta com a permanência do homem no campo, pelo fato de sofrer pouco com as oscilações do clima, o que não ocorre com a maioria das espécies agrícolas (VIDOR et al., 2002; LUZ et al., 2017).

A Região Sul é a principal responsável pela produção de erva-mate (ZANIN; MEYERM, 2018). Sendo o Estado do Paraná o mais importante para a produção nacional, em segundo 
lugar tem-se o Estado de Santa Catarina seguido pelo Rio Grande do Sul. Fora da região sul existe uma pequena produção, quase inexpressiva, do Estado do Mato Grosso do Sul, região centro-oeste (JUNQUEIRA et al., 2017). A produção desses quatros estados garante ao Brasil o título de maior produtor mundial de erva-mate. Para a média do período 2010-2014, a produção Brasileira foi de 573 mil toneladas, seguida por 243 mil toneladas na Argentina e de 80 mil toneladas no Paraguai (FA0, 2018).

Um processo é uma ordenação especifica das atividades de trabalho no tempo e no espaço com um começo e um fim, com inputs (entradas) e outputs (saídas) claramente identificados, definindo assim uma estrutura para ação (DAVENPORT, 1994). 0 processo é visto como um grupo de tarefas interligadas logicamente que utiliza os recursos da organização para gerar os resultados definidos, de forma a apoiar os seus objetivos (CORRÊA; CORRÊA, 2012; BALDAM et al., 2014).

As empresas atuais apresentam processos de produção bastante complexos, trabalhando com uma variedade de produtos muito maior. Com isso se torna difícil para organização identificar gargalos dentro do processo (LIMA; MARTINS, 2017).

Nesse sentido o mapeamento de processos é uma ferramenta extremamente reconhecida pelo importante papel que pode desempenhar, pois auxilia na avaliação de desempenho e no entendimento das dimensões estruturais do fluxo de trabalho, subsidiando programas de projeto das atividades (LAGE JÚNIOR, 2016). Mapear ajuda a identificar fontes de desperdício, fornecendo uma linguagem comum para o tratamento dos processos de manufatura e serviços, tornando as decisões de fluxo visíveis. Desse modo, permite discuti-las, agregando conceitos e técnicas enxutas, formando a base para um plano de implementação e mostrando a relação entre fluxo de informações e o fluxo de materiais (DATZ et al., 2004), além de delegar responsabilidades e promover o uso adequado dos recursos disponíveis (SANTOS et al., 2017).

A orientação do fluxo também é um benefício importante proporcionado pelo mapeamento do processo, pois permite transformar um simples layout de máquinas em uma série de processos de uma fábrica, de modo a reduzir distâncias entre operações, melhoras o aproveitamento do espaço e diminuição no tempo de produção. Muitas são as técnicas de representação usadas para construir modelos de processos que auxiliam a elaboração de diferentes tipos de mapas (LAGE JÚNIOR, 2016).

A análise crítica dos diagramas e a comparação destes com as fases e sequenciamento reais ajudam na identificação de possíveis problemas de qualidade, além de evidenciar 
desperdício, excesso de estoques e movimentações lentas (FABRÍCI0 et al., 2017). Dependendo da análise a que se propõem, os diagramas poderão conter informações adicionais, como tempo de cada fase, as quantidades estocadas, as distâncias percorridas, as fases de contato com os clientes (PINHO et al., 2007).

0 fluxograma é fundamental para a padronização e posterior entendimento do processo e consiste em registrar um processo de maneira compacta, a fim de tornar possível sua melhor compreensão para posterior melhoria. É um gráfico que representa os diversos passos ou eventos que ocorrem durante a execução de um processo, identificando etapas de ação (realização de uma atividade), inspeção, transporte, espera e fluxo de documentos e registros (CURY, 2017). Tipos diferentes de operação são designados por diferentes símbolos típicos (JHONSTON; CLARK, 2002).

Diante do exposto o objetivo do presente trabalho foi mapear o processo produtivo de dois tipos de erva-mate, para comercialização nacional e tipo exportação para o Uruguai, de uma ervateira localizada no norte do Estado de Santa Catarina.

\section{MATERIAL E MÉTODOS}

0 trabalho foi realizado na ervateira Bonetes, empresa fundada em 1995 que está localizada no município de Canoinhas - SC, na rodovia SC 477. Com uma estrutura de 2500 metros quadrados, equipamentos modernos para produção de erva-mate e 60 funcionários, sendo classificada como uma empresa de pequeno porte de acordo com SEBRAE (2015).

A coleta de dados foi realizada pelo acompanhamento das atividades dos responsáveis pelos setores da empresa, o que possibilitou uma visão macro do funcionamento industrial.

A referida empresa tem dois produtos principais, 55\% de sua produção são de ervamate para mercado nacional, os outros 45\% são de erva-mate tipo exportação, vendida para 0 Uruguai. As matérias-primas para cada uma são diferentes, a primeira vem do extrativismo, colhida de árvores sob a sombra da floresta ombrófila mista, e o tipo exportação são oriundas de povoamentos plantados a pleno sol. A justificativa para essa diferença vem do fato das folhas da erva-mate de pleno sol apresentarem um amargor muito mais intenso do que às sombreadas, por tanto, tem a preferência do mercado consumidor uruguaio, além da diferença de matérias-primas os dois tipos de erva-mate têm processos produtivos distinto.

No presente trabalho foram utilizados métodos qualitativos por meio da pesquisa bibliográfica e estudo de caso. Através de observação e consulta ao responsável do setor foi 
feito o mapeamento do processo produtivo dos dois principais produtos da ervateira, desde a escala macro até a mais detalhada.

0 mapeamento do processo foi empregado para representar os processos correlacionados. De acordo com Biazzo (2000) o procedimento para realizar o mapeamento de processo segue, normalmente, as seguintes etapas:

a) definição das fronteiras e dos clientes do processo, dos principais inputs e outputs (SIPOC) e dos atores envolvidos no fluxo de trabalho;

b) consulta com os responsáveis pelas várias atividades dentro do processo e estudo dos documentos disponíveis, a fim de coletar informações suficientes para reprodução do processo no mapeamento;

c) criação do mapa do processo com base na informação adquirida e revisão passo a passo do mapeamento.

A análise SIP0C (Suppliers, Inputs, Process, Outputs e Customers), em português, fornecedores, entradas, processo e cliente é empregada para identificar todos os elementos relevantes de um projeto antes do início deste (PANDE, 2000; RASIS et al., 2002; WERKEMA, 2012; R0MEIR0 et al., 2017; ALSUBAIE; YANGY, 2018). Através dela é possível ter a visão de todas as inter-relações dentro do processo, evidenciando suas interfaces e o impacto destas interfaces na qualidade do output e contribuindo assim para desenvolver um macro entendimento da organização voltada para o processo (RÉGIS et al., 2018).

Segundo Mello et al. (2009), o fornecedor pode ser externo ou interno, sendo responsável por proporcionar as entradas necessárias; a entrada é o que será transformado durante o processo; processo é a sequência das atividades que levam a um resultado esperado; saída é o produto ou serviço obtido após o processo para atender o cliente; cliente é quem recebe o produto ou serviço.

Para a construção de um fluxograma ou mapa de processo, é preciso que haja sequência lógica das atividades produtivas constituintes do processo (BATISTA et al. 2006). A sequência do processo deve ser apresentada listando-se os símbolos identificadores segundo a ordem de ocorrência e ligando-os por segmentos de reta, que representam o fluxo do item. Esse gráfico tem início com a entrada dos insumos e segue em cada passo como transportes, armazenamentos, inspeções, montagens, até que se tornem um produto acabado ou parte de um subconjunto, registrando-se o andamento do processo por um ou mais departamentos (LOBATO; LIMA, 2010). 
Este tipo de mapa usa diversos símbolos, os símbolos usados no presente trabalho se encontram na Figura 2.
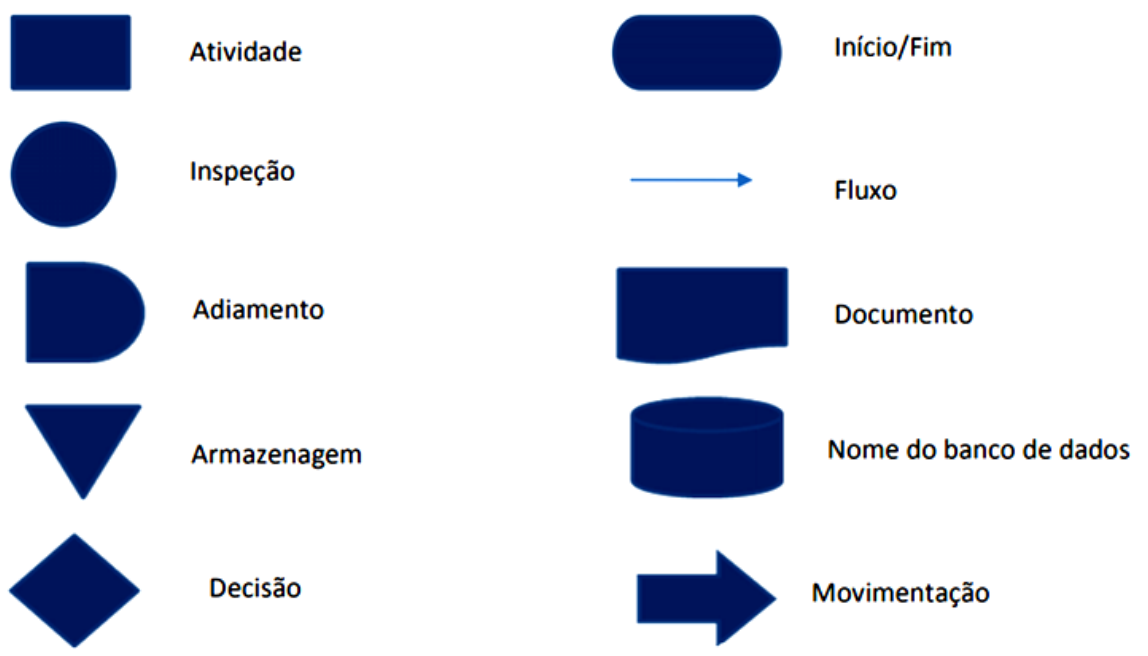

Figura 2. Símbolos para fluxograma Fonte: 0 s autores.

0 posicionamento dos processos foi utilizado para verificar o congestionamento de fluxo dentro das atividades. Essa técnica de mapeamento representa as atividades na área/setor em que são realizadas, identificando cruzamentos e trajetos do processamento (CURY, 2017).

Para o desenvolvimento desde mapa foi utilizada a planta industrial como base e posicionados os processos identificados pela matriz SIPOC.

Um layout bem alinhado com o processo pode reduzir os custos de produção, estocagem de materiais e o transporte ao decorrer dos processos produtivos. Alguns propósitos de layout de instalação orientam que estes devem estar ligados a estratégias de operação, tendo como precedências, baixos custos, qualidade nos produtos e serviços, entregas de menores prazo e entregas no período certo, flexibilidade no volume e produtos (GAITHER; FRAZIER, 2002).

\section{RESULTADOS E DISCUSSÃ0}

A produção de erva-mate para o mercado nacional possui em sua estrutura organizacional cinco setores responsáveis por oito processos principais. A Tabela 1 apresenta 
a matriz SIP0C da produção de erva-mate para o mercado nacional com os oito principais processos de produção.

No processo de pesagem/triagem a erva-mate em folha proveniente de pequenos produtores rurais é pesada e encaminhada ao setor de compras. 0 setor de compras encaminha a erva-mate in natura para o setor de secagem onde se inicia o processamento do material, reduzindo o teor de umidade das folhas.

A presença de água na erva-mate pode favorecer o aparecimento de fungos que podem degradar as folhas, tornando as nocivas ou não palatáveis, contudo a Resolução n ${ }^{\circ} 277$ de 22 de setembro de 2005 da Agência Nacional de Vigilância Sanitária, que regulamenta os produtos solúveis, não fixa um teor de umidade para o referido produto (ANVISA, 2005).

Após a secagem a erva-mate com baixo teor de umidade, ainda no setor de secagem, passa pelo processo de cancheamento ocasionando a redução do tamanho das folhas, seguindo para 0 setor de elaboração.

Neste setor a erva-mate cancheada passa pelo processo de elaboração, resultando na erva-mate moída que seguirá para o setor de empacotamento.

No setor de empacotamento a erva-mate é empacotada em embalagem de papel de um quilo, a cada cinco desses pacotes é formado um fardo, que é considerado o produto acabado. Esse produto acabado será encaminhado ao setor de expedição onde acontece a venda para 0 consumidor final.

Na ervateira estudada o destino final da erva-mate do mercado nacional é distribuído aos três estados da região sul, sendo 70\% para o Rio Grande do Sul, 20\% para Santa Catarina e 10\% para o Paraná.

Para o mercado nacional foram identificados, além dos oito processos principais, trinta e quatro sub-processos e quarenta atividades específicas. 0 processo principal mais complexo é o de secagem da erva-mate, com nove sub-processos, o mais simples, com dois subprocessos, é o de expedição.

A portaria No $118-\mathrm{N}$ de 12 de novembro de 1992 do Instituto Brasileiro do Meio Ambiente e dos Recursos Naturais discorre sobre classificação de produtos da erva-mate. A referida portaria determina que a erva-mate Padrão Uruguai (PU) deve conter no mínimo 50\% de folhas de erva-mate e o restante de aditivos, pó, palitos ou goma, além de ser passada em peneiras de número 14 a 50. A Tabela 2 apresenta a matriz SIP0C de produção para o mercado uruguaio.

No processo de pesagem/triagem a erva-mate é pesada e encaminhada ao setor de compras. 0 setor de compras encaminha a erva mate in natura para o setor de secagem onde 
se inicia o processamento do material, reduzindo o teor de umidade das folhas juntamente com a classificação do palito e pó das folhas. As folhas seguem para cancheamento ocasionando a redução do tamanho destas, sendo ensacadas dentro do setor de secagem. 0 pó e os palitos são armazenados para seguirem para o processo de elaboração.

Tabela 1. Matriz SIP0C do processo produtivo de erva-mate para o mercado nacional

\begin{tabular}{|c|c|c|c|c|}
\hline SUPPLIER & INPUT & PROCESS & OUTPUT & CUSTOMER \\
\hline $\begin{array}{l}\text { Pequenos produtores } \\
\text { rurais }\end{array}$ & Erva em folha & Pesagem/triagem & Erva nativa in natura & Setor de compras \\
\hline Setor de compras & Erva nativa in natura & Secagem & $\begin{array}{l}\text { Erva com baixo teor de } \\
\text { umidade }\end{array}$ & Setor de secagem \\
\hline Setor de Secagem & $\begin{array}{l}\text { Erva com baixo teor de } \\
\text { umidade }\end{array}$ & Cancheamento & Erva cancheada & Setor de secagem \\
\hline Setor de secagem & Erva cancheada & Elaboração & Erva moida & Setor de elaboração \\
\hline Setor de elaboração & Erva moída & Empacotamento & Erva empacotada & $\begin{array}{l}\text { Setor de } \\
\text { empacotamento }\end{array}$ \\
\hline $\begin{array}{l}\text { Setor de } \\
\text { empacotamento }\end{array}$ & Erva empacotada & Enfardamento & Produto acabado & $\begin{array}{l}\text { Setor de } \\
\text { empacotamento }\end{array}$ \\
\hline $\begin{array}{l}\text { Setor de } \\
\text { empacotamento }\end{array}$ & Produto acabado & Expedição & Produto acabado & Setor de expedição \\
\hline Setor de expedição & Produto acabado & Compra & Produto acabado vendido & Consumidor final \\
\hline
\end{tabular}

Fonte: Os autores

Tabela 2. Matriz SIPOC do processo produtivo de erva-mate para o mercado uruguaio

\begin{tabular}{|c|c|c|c|c|}
\hline Supplier & Input & Process & Output & Customer \\
\hline $\begin{array}{l}\text { Pequenos produtores } \\
\text { rurais }\end{array}$ & Erva em folha & Pesagem/triagem & Erva plantada in natura & Setor de compras \\
\hline Setor de compras & Erva nativa in natura & Secagem & Erva com baixo teor de umidade & Setor de secagem \\
\hline Setor de Secagem & $\begin{array}{l}\text { Erva com baixo teor de } \\
\text { umidade }\end{array}$ & Peneiração & $\begin{array}{l}\text { Erva com baixo teor de umidade }+ \\
\text { palito }+ \text { pó }\end{array}$ & Setor de secagem \\
\hline Setor de Secagem & $\begin{array}{l}\text { Erva com baixo teor de } \\
\text { umidade }\end{array}$ & Cancheamento & Erva cancheada & Setor de secagem \\
\hline Setor de Secagem & Erva cancheada & Ensacamento & Erva ensacada cancheada & Setor de secagem \\
\hline Setor de secagem & Erva ensacada & Amarelamento & Erva amarela cancheada & Setor de secagem \\
\hline Setor de secagem & Erva amarelada & Peneiração & Erva amarela peneirada & Setor de exportação \\
\hline Setor de exportação & Erva amarela peneirada & & & \\
\hline $\begin{array}{l}\text { Setor de secagem } \\
\text { Terceiro }\end{array}$ & $\begin{array}{l}\text { Palito + pó } \\
\text { Pó }\end{array}$ & Elaboração & Erva tipo exportação & Setor de exportação \\
\hline Setor de exportação & Erva tipo exportação & Empacotamento & Erva empacotada tipo exportação & $\begin{array}{l}\text { Setor de } \\
\text { empacotamento }\end{array}$ \\
\hline $\begin{array}{l}\text { Setor de } \\
\text { empacotamento }\end{array}$ & $\begin{array}{l}\text { Erva empacotada tipo } \\
\text { exportação }\end{array}$ & Enfardamento & Produto acabado tipo exportação & $\begin{array}{l}\text { Setor de } \\
\text { empacotamento }\end{array}$ \\
\hline $\begin{array}{l}\text { Setor de } \\
\text { empacotamento }\end{array}$ & $\begin{array}{l}\text { Produto acabado tipo } \\
\text { exportação }\end{array}$ & Expedição & Produto acabado tipo exportação & Setor de expedição \\
\hline Setor de expedição & $\begin{array}{l}\text { Produto acabado tipo } \\
\text { exportação }\end{array}$ & Compra & $\begin{array}{l}\text { Produto acabado tipo exportação } \\
\text { vendido }\end{array}$ & Consumidor final \\
\hline
\end{tabular}

Fonte: Os autores

A erva-mate cancheada e ensacada segue para o processo de amarelamento em estufa por um período de 90 dias dentro do setor de secagem. Após o amarelamento, a erva-mate é peneirada seguindo o padrão uruguaio e encaminhada ao setor de exportação para elaboração e dosagem das respectivas quantidades de pó, palito e erva-mate amarelada seguindo o 
padrão uruguaio. Dentro do processo de elaboração, a matéria prima é recebida de três clientes: o setor de secagem como fornecedor pó e palito; setor de exportação que fornece folha amarelada; e terceiros para o fornecimento de pó de erva-mate devido à baixa produção deste pela ervateira.

Após a elaboração a erva-mate segue para o empacotamento e enfardamento dentro do setor de empacotamento gerando o produto acabado que será expedido pelo setor de expedição. 0 produto acabado é comprado por uma importadora do Uruguai.

A produção da erva-mate padrão uruguaio é muito mais complicada do que a destinada ao mercado nacional, com 12 processos principais, quarenta e oito sub-processos e cinquenta e cinco atividades específicas. Contudo a secagem e a expedição se mantiveram como o mais complexo e o mais simples respectivamente.

Ao estudarem a influência das etapas do processo industrial nas características físicoquímica da erva-mate Esmelindro et al. (2002) constataram que devido às altas temperaturas utilizadas a secagem é o processo que mais afeta os teores dos compostos presentes na ervamate.

Com as informações coletadas, foi possível mapear as atividades desenvolvidas. A Figura 3 apresenta o mapa desenvolvido para caracterização e avaliação do macroprocesso de produção de erva-mate para o mercado nacional e a Figura 4 para o mercado uruguaio.

Na Argentina a erva-mate é produzida de maneira mais sucinta, Burtinik (2006) descreve sete processos principais utilizados nas ervateiras argentinas. 0 autor supracitado destaca que para se alcançar maior amargor são utilizadas folhas de árvores plantadas a pleno sol, além da presença da etapa de amarelamento, portando, apesar da erva-mate da Argentina vir de um processo produtivo mais curto, é buscado um produto final semelhante à erva-mate padrão uruguaio produzido no Brasil. 


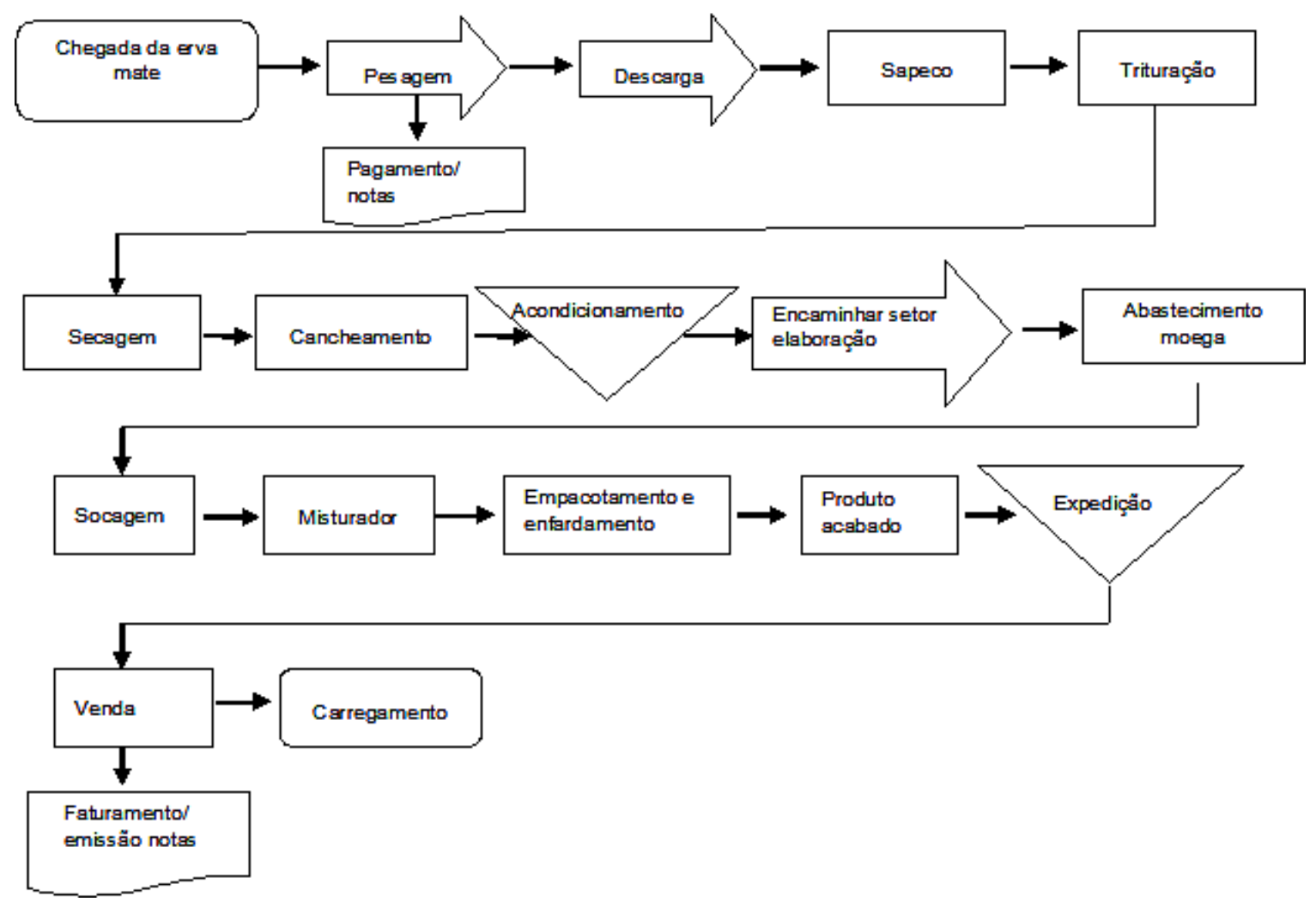

Figura 3. Mapa do macroprocesso de produção de erva-mate para o mercado nacional Fonte: 0s Autores.

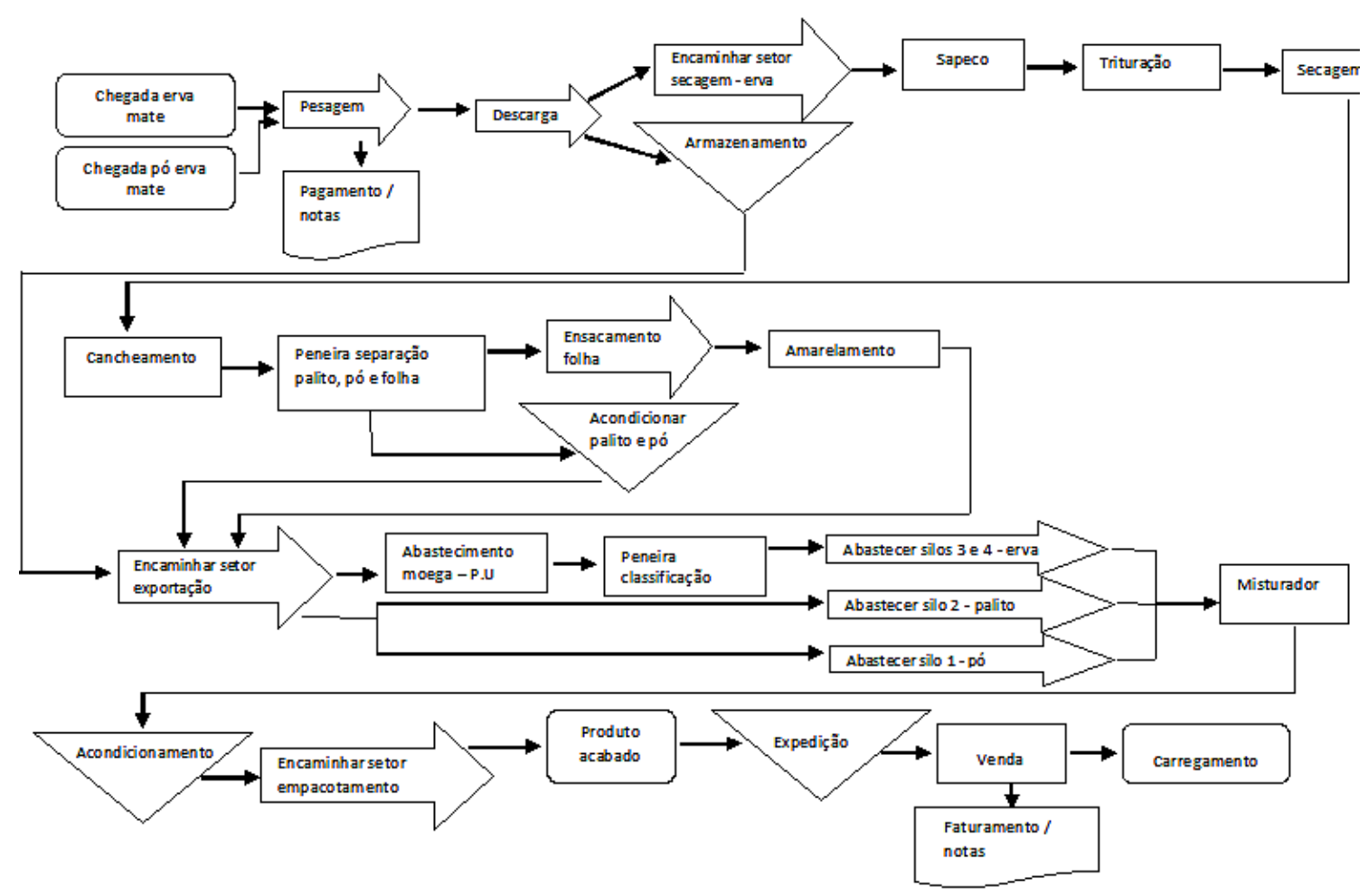

Figura 4. Mapa do macroprocesso de produção de erva-mate para o mercado uruguaio Fonte: 0 s autores. 
De acordo com os mapas apresentados nas Figuras 3 e 4, é possível identificar a maior complexidade na produção da erva-mate padrão uruguaio. Na chegada da matéria-prima, além da erva-mate em folhas, é recebido o pó de erva-mate oriundo do processamento de outras indústrias ervateiras da região.

As folhas de erva-mate são pesadas, descarregadas e encaminhadas para o setor de secagem onde será realizado os processos de sapeco, trituração, secagem e cancheamento e de forma similar em ambos produtos da empresa.

0 processo de sapeco é onde acontece a retirada de impurezas e a desidratação das folhas de erva-mate. Logo após, a erva-mate passa por um triturador e cai dentro do secador onde acontece o processo de secagem das folhas. Em seguida, a erva-mate triturada passa novamente por um processo de cancheamento, e cai diretamente no bag onde ficará acondicionado. A erva-mate destinada ao mercado nacional será encaminhada para o setor de elaboração, onde passará pelo processo de socagem e homogeneização, sendo na sequência empacotada, enfardada e encaminhada para expedição.

No processo produtivo de erva-mate padrão uruguaio, após o cancheamento, a ervamate é peneirada para separar o pó, palito e folha, sendo o palito e o pó armazenados para etapa de elaboração e a folha será ensacada por dois funcionários para a etapa seguinte, o amarelamento. 0 processo de amarelamento da erva-mate cancheada ocorre através do acondicionamento na estufa $75^{\circ} \mathrm{C}$ por 90 dias, depois desse tempo a erva-mate é retirada e encaminhada para o setor de exportação onde ocorrerá 0 peneiramento da erva-mate cancheada amarela. Esta erva-mate então abastecerá dois silos, sendo os outros dois abastecidos um com pó e outro com palito. Quando todos os silos estiverem cheios o operador irá ligar as roscas de saída e será dado início na homogeneização. A erva-mate padrão uruguaio irá cair dentro de um bag e será encaminhada para o setor de empacotamento. Nesse setor, o operador deverá abastecer as moegas do misturador com erva-mate homogeneizada, iniciando o empacotamento e enfardamento. Quando o fardo estiver pronto será acondicionado em paletes e direcionado ao setor de expedição.

A Figura 5 apresenta o posicionamento dos processos produtivos identificados pela análise SIPOC para produção de erva-mate para o mercado nacional (A) e para o mercado uruguaio (B). 

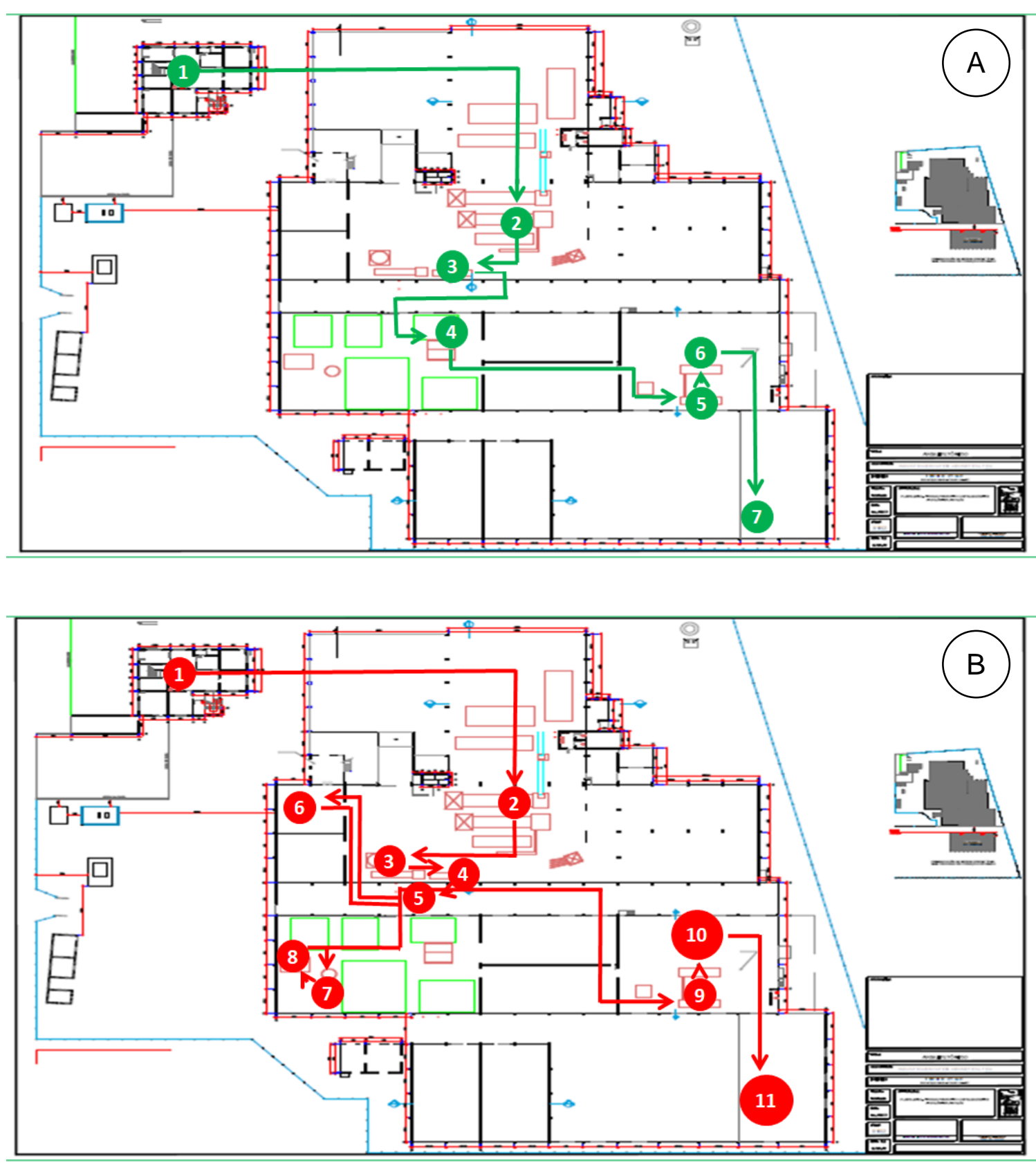

Figura 5. A: Posicionamento dos processos produtivos da erva-mate mercado nacional; B: Posicionamento dos processos produtivos da erva-mate padrão uruguaio. Fonte: 0s autores.

Processos com diversos cruzamentos se caracterizam por apresentarem grande volume de funcionários em mesmo espaço para a movimentação da matéria-prima, elevadas distâncias de movimentação que causam perda de tempo com deslocamento e, conseguintemente, redução no rendimento do processo. Já um sistema com menor movimentação de materiais proporciona redução de custos de mão-de-obra, de materiais e 
equipamentos, melhora capacidade produtiva, melhores condições de trabalho e maior segurança (FRANCISCHINI; GURGEL, 2013).

A complexidade da produção da erva-mate padrão uruguaio refletiu no caminho dos processos produtivos dentro da planta, com trajetos que se cruzam em vários momentos, enquanto que a erva-mate para o mercado nacional percorre trajeto curto que nunca se sobrepõe. A maior distância de movimentação e maior número de cruzamentos na linha de produção tornam a produção da erva-mate padrão uruguaio mais onerosa e demorada do que a para mercado nacional

\section{CONCLUSÃO}

A análise SIPOC e o mapeamento de processos como ferramentas gerenciais possibilitaram a visualização dos processos relacionados com a produção de erva-mate, desde a escala macro até a mais detalhada, assim como o relacionamento entre as atividades envolvidas.

Foram identificados oito processos, trinta e quatro subprocessos e quarenta atividades específicas para produção de erva-mate tipo nacional e doze processos, quarenta e oito subprocessos e cinquenta e cinco atividades específicas para produção de erva-mate padrão uruguaio, mostrando a maior complexidade desse processo produtivo.

Para se produzir a erva-mate padrão uruguaio tem-se maiores distâncias de deslocamento de matéria-prima e maior número de cruzamentos na linha de produção.

Para trabalhos futuros sugere-se determinar as variáveis operacionais de cada processo, bem como os parâmetros de qualidade da erva-mate ao longo da produção.

\section{AGRADECIMENT0}

Os autores agradecem aos gestores da Ervateira Bonetes por conceder acesso à empresa para realização do presente trabalho.

\section{REFERÊNCIAS BIBLIOGRÁFICAS}

AGÊNCIA NACIONAL DE VIGILÂNCIA SANITÁRIA. Resolução $\mathrm{n}^{\circ}$ 277, de 22 de setembro de 2005. Aprova 0 regulamento técnico para café, cevada, chá, erva-mate e produtos solúveis. Diário Oficial da União, Brasília, DF, n. 184, 23 set. 2005. Seção 1, p. 379. 
ALSUBAIE, B.; YANG, Q. Maintenance Process Improvement Model by Integrating LSS and TPM for Service Organisations. In: ZUO, M.; MA, L.; MATHEW, J.; HUANG, H. Z. (Ed.). Engineering Asset Management 2016. Lecture Notes in Mechanical Engineering. Cham: Springer, 2018. p. 13-24.

BALDAM, R.; VALE, R.; ROZENFELD, H. Gerenciamento de processos de negócio BPM. Rio de Janeiro: Campus, 2014.

BATISTA, G. R.; LIMA, M. C. C.; GONÇALVES, V. S. B.; SOUTO, M .S. M. L. Análise do processo produtivo: um estudo comparativo dos recursos esquemáticos. XXVI ENEGEP - Encontro Nacional de Engenharia de Produção, FortalezaCE, Out 2006. Disponível em: http://www.abepro.org.br/biblioteca/enegep2006_TR450307_7954.pdf. Acesso em 28 de janeiro de 2018.

BERTÉ, K. A. S. Tecnologia da erva-mate solúvel. 2011. 160 f. Tese (Doutorado em Tecnologia de Alimentos) - Setor de Tecnologia - Universidade Federal do Paraná, Curitiba. 2011.

BIAZZ0, S. Approaches to business process analysis: a review. Business Process Management Journal, Bingley, v. 6 , n. 2, p. 99-112, 2000.

BORILLE, Â. M. W.; REISSMANN, C. B.; FREITAS, R. J. S. Relação entre compostos fitoquímicos e o nitrogênio em morfotipos de erva-mate (Ilex paraguariensis St. Hil.). Boletim do Centro de Pesquisa de Processamento de Alimentos, Curitiba, v. 23, n. 01, p.183-198, 2005.

BURTNIK, O. J. Yerba mate: Manual de producción, 3. ed. Corrientes: INTA, 2006.

CARDOSO, A. S.; GROISMAN, A. Ação e interação: uma etnografia dogauchismo no ciberespaço. Revista Internacionalde Folkcomunicação, Pelotas, v. 15, n. 35, p. 122-140, 2018. Disponível em: http://revistas.uepg.br/index.php/folkcom/article/view/2280/1555. Acesso em 02 de fevereiro de 2018.

CATANDUVAS. Benefícios da erva mate, 2018. Disponível em: http://www.catanduvas.com/erva-mate/. Acesso em 02 de fevereiro de 2018.

CHECHI, L. A.; SCHULTZ; G.; FERRPNATTO, E. M. 0.; MONTAGNER, J. M. ATIVOS TERRITORIAIS E DESENVOLVIMENTO: ESTUDO DA ARTICULAÇÃO PELA INDICAÇÃO GEOGRÁFICA DA ERVA-MATE NO POLO ERVATEIRO ALTO TAQUARI - RS. Estratégia e Desenvolvimento, Santana do Livramento, v. 1, n. 1, p. 16-34, 2017. Disponível em: http://seer.unipampa.edu.br/index.php/red/article/view/17258. Acesso em 28 de janeiro de 2018.

CORRÊA, H. L.; CORRÊA, C. A. Administração de Produção e Operações. 3. ed. São Paulo: Atlas, 2012.

CURY, A. Organização e métodos: uma visão holística. 9. ed. São Paulo: Atlas, 2017.

DIAZ, V. S.; SEOANE, C. E. S.; KAGEYAMA, P. Y.; SEBBENN, A. M. Diversidade genética, estrutura genética espacial e fluxo gênico em populações de erva-mate (Ilex paraguariensis A. St. Hil.) na área de entorno do Parque Nacional do Iguaçu. Colombo: Embrapa Florestas, 2013. 48p.

DATZ, D.; MELO, A. C. S. M; FERNANDES, E. Mapeamento de Processos como Instrumento de Apoio à Implementação do Custeio Baseado em Atividades nas Organizações. XXIV ENEGEP - Encontro Nacional de Engenharia de Produção, Florianópolis-SC, $\quad$ Nov 2004. Disponível em: http://www.abepro.org.br/biblioteca/ENEGEP2004_Enegep0302_0606.pdf. Acessado em 14 de setembro de 2017.

DAVENPORT, D. R. Reengenharia de processos: como inovar na empresa através da tecnologia da informação. Rio de Janeiro: Campus, 1994.

ESMELINDR0, M. C.; TONIAZZ0, G.; WACZUK, A.; DARIVA, C.; OLIVEIRA, D. D. Caracterização físico-química da ervamate: influência das etapas do processamento industrial. Ciência e Tecnologia de Alimentos, Campinas, v. 22, n. 02, p. 193-204, 2002. Disponível em: http://www.scielo.br/pdf/cta/v22n2/al6v22n2.pdf. Acessado em 28 de janeiro de 2018.

FABRICIO, A.; HOSS, M., GODOY,L. P.; PINHEIRO, E.; CEMBRANEL, P. Proposta de metodologia para identificação de perdas produtivas: um estudo em padaria e confeitaria. Revista de Administração e Comércio Exterior, Passo

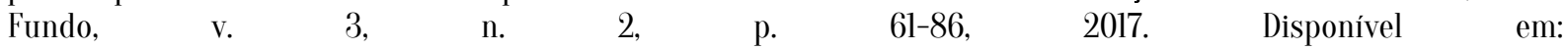


http://seer.faculdadejoaopaulo.edu.br/index.php/racex/article/view/105/151. Acessado em 02 de fevereiro de 2018 .

FOOD AND AGRICULTURE ORGANIZATION OF THE UNITED NATIONS. Faostat 2018. Disponível em: http://www.fao.org/faostat/en/\#data/QC. Acessado em 29 de março de 2018.

FRANCISCHINI, P. G.; GURGEL, F. A. Administração de materiais e do patrimônio. 2. ed. São Paulo: Cengage, 2013

GAITHER, N.; FRAZIER, G. Administração da produção e operações. 8. ed. São Paulo: Pioneira Thomson, 2002.

INSTITUTO BRASILEIR0 DO MEI0 AMBIENTE E DOS RECURSOS NATURAIS RENOVÁVEIS. Portaria Normativa Nº 118N/92. Dispõe sobre as pessoas físicas ou jurídicas envolvidas na exploração, beneficiamento e/ou comercialização da erva-mate (Ilex paraguariensis). Diário Oficial da União, Brasília, DF, n. 217, 12 nov. 1992, Seção 1, p. 50.

JUNQUEIRA, A. A.; BASSO, V. M.; SOUZA, N. D. Evolução da extração vegetal de erva-mate no período de 2004 a 2015. In: I Semana de Aperfeiçoamento em Engenharia Florestal, 2017, Curitiba. Anais... Curitiba: UFPR, 2017.

LAGE JÚNIOR, M. Mapeamento de processos de gestão empresarial. Curitiba: Intersaberes, 2016.

LIMA, P. R. B.; MARTINS, V. W. B. Sistema lean para otimização de recursos em uma indústria moveleira: estudo de caso com foco nas ferramentas da produção enxuta. Revista Gestão Industrial, Ponta Grossa, v. 13, n. 3, p. 112-140, 2017.

LOBATO, K. C. D; LIMA, J. P. Characterization and evaluation of selection processes of urban solid waste through mapping technique. Engenharia Sanitária e Ambiental, Curitiba, v.15 n.4, p. 347-356, 2010. Disponível em: http://www.scielo.br/pdf/esa/vl5n4/a07vl5n4. Acesso em 28 de janeiro de 2018.

LUZ, M.; DAL SOGLIO, F. K.; KUBO, R. R. Resistência camponesa no âmbito da fabricação artesanal de erva-mate, Rio Grande do Sul,Brasil. Revista Brasileira de Agroecologia, Pelotas, v. 12, n. 1, p. 68-80, 2017. Disponível em: http://revistas.aba-agroecologia.org.br/index.php/rbagroecologia/article/view/16068/12663. Acessado m $02 \mathrm{de}$ fevereiro de 2018.

MELLO, C. H. P.; DA SILVA, C. E. S.; TURRIONI, J. B. DE SOUZO, L. G. M. IS0 9001:2008. Sistema de gestão da qualidade para operações de produção e serviço. São Paulo: Atlas, 2009.

MURAKAMI, A. N. N.; AMBONI, R. D. M. C.; PRUDÊNCIO, E. S.; AMANTE, E. R.; FRITZEN-FREIRE, C. B.; BOAVENTURA, B. C. B.; MUÑOZ, I. B.; BRANCO, C. S.; SALVADOR, M.; MARASCHIN, M. Concentration of biologically active compounds extracted from Ilex paraguariensis St. Hil. By nanofiltration. Food Chemistry, Rockville Pike, v. 141, n. 1, p. 60-65, 2013. Disponível em: https://www.sciencedirect.com/science/article/pii/S0308814613002823?via\%3Dihub. Acessado em 02 de fevereiro de 2018.

PANDE, P. S.; NEUMAN, R. P.; CAVANAGH, R. R. The six sigma way: how GE, Motorola, and other top companies are honing their performance. New York: McGraw- Hill, 2000.

PERALTA, R.; LE BOURLEGAT, C. A. Trajetória da produção e da comercialização da erva-mate na fronteira sul de mato grosso do sul. Geografia Agrária, Uberlândia, v. 07, n. 13, p. 188-209, 2012. Disponível em: http://www.seer.ufu.br/index.php/campoterritorio/article/view/13750. Acessado em 28 de janeiro de 2018

PINHO, A. F.; LEAL, F; MONTEVECHI, J. A. B.; ALMEIDA, D. A. Combinação entre as Técnicas de Fluxograma e Mapa de Processos no Mapeamento de um Processo Produtivo. XXVII ENEGEP - Encontro Nacional de Engenharia de Produção, Foz do Iguaçu-PR, Out/ $2007 . \quad$ Disponível http://www.abepro.org.br/biblioteca/ENEGEP2007_TR570434_9458.pdf. Acessado em 14 de setembro de 2017.

RASIS, D.; GITLOW, H. S.; POOVICH, E. Paper organizers international: a fictitious Six Sigma Green Belt case study. I. Quality Engineering, New York, v. 15, n. 1, p. 127-145, 2002.

RÉGIS, T. K.0.; GOHR, C. F.; SANTOS, L. C. Lean healthcare implementation: experiences and lessons learned from brazilian hospitals. Journal of Busines Management, São Paulo, v. 58, n. 1, p. 30-43, 2018. 
ROMEIR0, S. C.; ARAÚJ0, M. A.; ARAÚJ0, F. C. 0 ESTUd0 DA CADEIA PRODUTIVA DO VIRABREQUIM PARA IDENTIFICAÇÃO DAS NÃO CONFORMIDADES UTILIZANDO AS FERRAMENTAS SIPOC E PDCA. E-locução, Extrema, v. 2 , n. 12, p. 81-99, 2017. Disponível em: http://periodicos.faex.edu.br/index.php/e-locucao/article/view/137/123. Acessado em 02 de fevereiro de 2018.

SANTOS, M.; MAGNO, B. D.; QUINTAL, R. S.; DIAS, F. C.; SANTOS, F. M. C.; MARTINS, E. R. Simulação de eventos discretos na identificação de gargalos no processo seletivo de estagiários de um órgão público federal: uma abordagem sistêmica. Universitas: Gestão e TI, Brasília, v. 7, n. 1-2, p. 149-155, 2017

JHONSTON, R.; CLARK, G. Administração de operações de serviços. São Paulo: Atlas, 2002.

SERVIÇO BRASILEIRO DE APOIO ÀS MICRO E PEQUENAS EMPRESEAS. Anuário do trabalho na micro e pequena empresa: 2014. 7. ed. São Paulo: SEBRAE, 2015.

SOUZA, V. C.; LORENZI, H. Botânica Sistemática: Guia ilustrado para identificação das famílias de Fanerógamas nativas e exóticas no Brasil, baseado em APG III. 3. ed. Nova Odessa: Plantarum, 2012.

VIDOR, M. A.; RUIZ, C. P.; MORENO, S. V.; FLOSS, P. A. Marcadores moleculares em estudos de caracterização de erva-mate (Ilex paraguariensis St. Hil.): o sabor. Ciência Rural, Santa Maria, v. 32, n. 03, p. 415-420, 2002.

WERKEMA, M. C. C. Criando a cultura Seis Sigma. 3. ed. Rio de Janeiro: Campus, 2012.

ZANIN, V.; MEYER, L. G. Evolução de comercialização da erva mate no Rio Grande do Sul. Revista iPecege, Piracicaba, v. 4, n. 1, p. 7-18, 2018. 